\title{
Copolymerization of 2,2-Diallyl-1,1,3,3-tetraethylquanidinium Chloride with N-(4-Acetylphenyl)maleimide
}

\author{
Marina N. Gorbunova \\ Institute of Technical Chemistry Ural Branch of Russian Academy of Sciences, Perm, 614013, Russia
}

\begin{abstract}
The free-radical copolymerization of 2,2-diallyl-1,1,3,3-tetraethylguanidinium chloride with N-(4- acetylphenyl)maleimide is studied in bulk and in organic solvents. It is shown that copolymerization in bulk and in solution proceeds to form copolymers with random distribution of monomer units. The kinetic laws of the reaction are investigated, and the relative activities of the monomers are determined. It is found that 2,2-diallyl-1,1,3,3-tetraethylguanidinium chloride is involved in copolymerization with $\mathrm{N}$-substituted maleimides to give rise to pyrrolidinium structures.
\end{abstract}

Keywords Radical Copolymerization, Quanidinium Salt, N-(4-Acetylphenyl)Maleimide, Kinetics

\section{Introduction}

Maleimides have found wide use as thermoreactive binders in engineering, electrical insulation, and technical items because materials formed on their basis are resistant to radiation and possess high fire resistance; moreover, their dielectric properties are stable up to $200-250^{\circ} \mathrm{C}[1]$. It is known that $N$-substituted maleimides homopolymerize according to the radical mechanism[2,3] and are involved in copolymerization with styrene[4-9], butadiene[4], (meth) acrylic acid and its esters[4,11], vinyl ethers[10-12], and vinylketones[13]. In copolymerization with electron-donor monomers, they, being electron acceptors, form copolymers with a high tendency of monomer units toward alternation $[4,9,11,12]$.

Compounds containing quanidine groups show a broad spectrum of bactericide effects, and they are used as medicines and fungicides[14-16]. That is why quanidine group introduction into high molecular-weight compounds is undoubtedly of interest.2,2-Diallyl-1,1,3,3-tetraethylguanid inium chloride(AGC) shows promise for this purpose.

The copolymerization of this monomer with $N$-phenyland $N$-p-carboxyphenylmaleimide was reported in[17]. It was shown that copolymerization proceeds to form copolymers with a high tendency toward alternation of monomer units.

No data is available on the copolymerization of AGC with $\mathrm{N}$-(4-acetylphenyl)maleimide; however, the synthesis and

* Corresponding author:

mngorb@newmail.ru (Marina N. Gorbunova)

Published online at http://journal.sapub.org/ajps

Copyright (C) 2012 Scientific \& Academic Publishing. All Rights Reserved characterization of copolymers based on AGC is of great interest since the mentioned compounds can be used in medicine and biotechnology.

In the present study, the copolymerization of $\mathrm{AGC}$ with $N$-(4-acetylphenyl)maleimide (APMI) was studied.

\section{Experimental}

\subsection{Materials}

2,2-Diallyl-1,1,3,3-tetraethylguanidinium chloride was synthesized as described in[18]. Tetraethylurea (1 mol) was dissolved in dry benzene $(2.5 \mathrm{~mol})$. Phosgene was bubbled through the solution at $9-15^{\circ} \mathrm{C}$ at the intensive stirring until the reaction was completed (control by gas-liquid chromatography). Then the reactive mixture was heated slowly and was boiled until the gas stopped emanating. It was followed by the cooling of the reactive mixture and dry diallylamine $(2.4 \mathrm{~mol})$ was added dropwise with the constant intensive stirring. Then the reactive mixture was stirred for two hours at $50-60^{\circ} \mathrm{C}$ and sodium hydroxide $(1.2 \mathrm{~mol}$ of $50 \%$ aqueous solution) was added dropwise to the mixture. After that the reaction mixture was filtered, the filtrate was evaporated under vacuum at $70^{\circ} \mathrm{C}$. The obtained AGC was thoroughly rinsed with dry acetone to remove the residual $\mathrm{NaCl}$. Finally, acetone was removed by distillation. The yield of AGC was $70 \%$ from the theory. The purity of AGC was determined via elemental analysis and ${ }^{13 \mathrm{C}} \mathrm{NMR}$ spectroscopy. According to elemental analysis, the contents of elements are as follows: $\mathrm{C}$, 62.42(calcd., 62.61); H, 10.67(calcd., 10.43); N, 14.58\% (calcd., 14.61); and $\mathrm{Cl}, 12.32 \%$ (calcd., 12.35). The chemical shifts $(\delta, \mathrm{ppm})$ and multiplicity of the ${ }^{13 \mathrm{C}} \mathrm{NMR}$ spectrum of AGC are given in Table 1 . 
APMI was synthesized as described in[19]; acetone was used as a solvent instead of ether. APMI $\left(\mathrm{T}_{\mathrm{m}}=151-153^{\circ} \mathrm{C}\right)$ was used in experiments. According to elemental analysis, the contents of elements in APMI are as follows: C, 67.41 (calcd., 66.98); H, 4.20 (calcd., 4.19), and N, 6.35\% (calcd., $6.50)$. The chemical shifts $(\delta, \mathrm{ppm})$ and multiplicity of the 13C NMR spectrum of maleimides are given in Table 1.

The structures of the monomers and polymers are schematically shown on Scheme 1 .

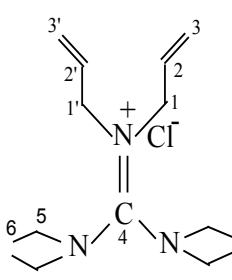

I

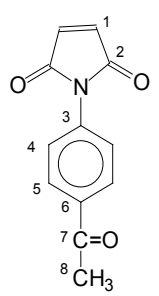

III

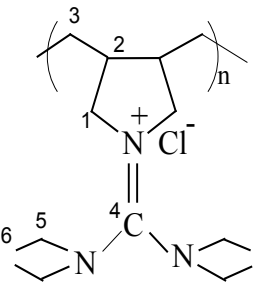

II

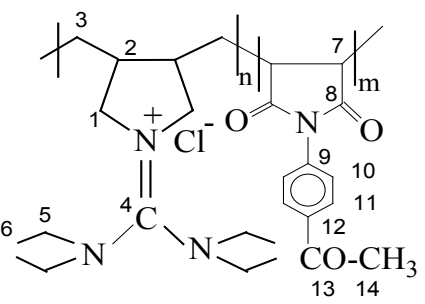

IV
Scheme 1. Structures of AGC (I), PAGC (II), APMI (III) and copolymer AGC-APMI (IV)

Initiator AIBN and solvents were purified by conventional methods; their characteristics corresponded to the literature data[20].

\subsection{Copolymerization}

Copolymerization of AGC with APMI was conducted in bulk and in organic solvents in the presence of $3.0 \cdot 10^{-2} \mathrm{~mol}$ $\mathrm{L}^{-1} \mathrm{AIBN}$. Copolymerization was studied for a molar fraction of AMI from approximately 0.8 to 0.2 in the feed. The kinetic investigations were carried out at initial conversions by the gravimetric method at $60-90^{\circ} \mathrm{C}$. The reaction was allowed to go on for less than $10 \%$ conversion therefore it was terminated stopped at a certain time. Copolymers were precipitated and purified by three-fold reprecipitation by a precipitant (water) from the solution. The purified copolymers were dried under vacuum at $50^{\circ} \mathrm{C}$ until constant weight was achieved. The copolymer composition was calculated from the elemental analysis data.

Effective reactivity ratios $r_{1}$ and $r_{2}$ were calculated via the Mayo-Lewis[21], Finemann-Ross[22], and Kelen- Tüdös [23] methods.

\subsection{Measurements}

The IR spectra were obtained on a IFS 66/S Bruker spectrometer in $\mathrm{KBr}$ tablets.

The ${ }^{1} \mathrm{H}$ and ${ }^{13} \mathrm{C}$ NMR spectra were recorded on a "Bruker AM-300" spectrometer operating at 300 and $75.47 \mathrm{MHz}$ using a broad-band proton suppression and in a JMOD mode. DMSO- $\mathrm{d}_{6}$ was used as solvent; tetramethylsilane(TMS) was used as internal standard.

The calorimetric measurements were performed on DSC unit Mettler-Toledo with a scan rate of 10 or $30^{\circ} \mathrm{C} \cdot \mathrm{min}^{-1}$.

The thermogravimetric and differential thermal analyses(TG/DTA) were carried out using TGA/DSC1 unit Mettler-Toledo at the heating rate of $10^{\circ} \mathrm{C} \cdot \mathrm{min}^{-1}$.

Molecular weight of copolymer was determined by sedimentation method $\left(25^{\circ} \mathrm{C},(30-40) \cdot 10^{3}\right.$ circle $\left./ \mathrm{min}\right)$.

Acute toxicity of the copolymers was measured in mongrel white male mice weighing 18-20 g, using intraperitoneal doses. The mice was injected with these copolymers. The dose was up to $1000 \mathrm{mg} \cdot \mathrm{kg}^{-1}$. Each group consisted of six animals. The animals were observed for $48 \mathrm{~h}$. $\mathrm{LD}_{50}$ values were calculated by Prozorovskiy's method[24].

Microbiological tests were performed by serial dilution of preparations in meat-peptone broth followed by inoculation of meat-peptone agar. Test cultures were Staphylococcus aureus strain 906, Staphylococcus saprophyticus, ATCC 15305, Micrococcus luteus, ATCC 4698, Escherichia coli strain 25922, Bacillus subtilis ATCC 6633, Salmonella euteriditis, Pseudomonas fluorescens NCIMB 9046. Bacteria were grown for $20 \mathrm{~h}$ or 7 days. Microbial loads were $2.5 \cdot 10^{5}$ cells in $1 \mathrm{ml}$ of preparation-containing liquid growth medium.

\section{Results and Discussion}

\subsection{Copolymerization of AGC with APMI}

The AGC with APMI copolymers were prepared by radical copolymerization in bulk and in DMFA at $80^{\circ} \mathrm{C}$ in the presence of AIBN as the radical initiator.

Table 1. NMR ${ }^{13} \mathrm{C}$ spectra of AGC (1), PAGC (2), APMI (3) and copolymer of AGC-APMI (4) (DMSO-d6, TMS, 25C)

\begin{tabular}{|c|c|c|c|c|c|c|c|c|c|c|c|c|c|c|}
\hline & & \multicolumn{13}{|c|}{ Chemical shift values and signals multiplets of the atoms $(\delta, \mathrm{ppm})$} \\
\hline & $\mathrm{C}^{1}$ & $\mathrm{C}^{2}$ & $\mathrm{C}^{3}$ & $\mathrm{C}^{4}$ & $\mathrm{C}^{5}$ & $\mathrm{C}^{6}$ & $\mathrm{C}^{7}$ & $\mathrm{C}^{8}$ & $\mathrm{C}^{9}$ & $\mathrm{C}^{10}$ & $\mathrm{C}^{11}$ & $\mathrm{C}^{12}$ & $\mathrm{C}^{13}$ & $\mathrm{C}^{14}$ \\
\hline I & $\begin{array}{c}54.56 \\
\mathrm{t}\end{array}$ & $\begin{array}{c}133.76 \\
\mathrm{~d}\end{array}$ & $\begin{array}{c}123.41 \\
\mathrm{t}\end{array}$ & $\begin{array}{c}165.71 \\
\mathrm{~s}\end{array}$ & $\begin{array}{c}45.83 \\
t\end{array}$ & $\begin{array}{c}14.48 \\
\mathrm{k}\end{array}$ & & & & & & & & \\
\hline II & 55.60 & $\begin{array}{c}43.49 \\
d\end{array}$ & 27.77 & $\begin{array}{c}162.30 \\
s\end{array}$ & 45.08 & $\begin{array}{c}14.95 \\
\mathrm{k}\end{array}$ & & & & & & & & \\
\hline III & $\begin{array}{c}134,91 \\
\text { д }\end{array}$ & $\begin{array}{c}169,65 \\
\mathrm{~s}\end{array}$ & $\begin{array}{c}135,80 \\
\mathrm{~S}\end{array}$ & $\begin{array}{c}126,28 \\
\mathrm{~d}\end{array}$ & $\begin{array}{c}128,96 \\
\mathrm{~d}\end{array}$ & $\begin{array}{c}135,54 \\
\mathrm{~d}\end{array}$ & $\begin{array}{c}197.35 \\
\mathrm{~s}\end{array}$ & $\begin{array}{c}26,89 \\
\mathrm{~s}\end{array}$ & & & & & & \\
\hline IV & $\begin{array}{c}52.13 \\
\mathrm{t}\end{array}$ & $\begin{array}{c}47.96 \\
\text { d }\end{array}$ & $\begin{array}{c}43.48 \\
\mathrm{t}\end{array}$ & $\begin{array}{c}172.88 \\
\mathrm{~s}\end{array}$ & $\begin{array}{c}41.84 \\
\mathrm{t}\end{array}$ & $\begin{array}{c}13.14 \\
\mathrm{k}\end{array}$ & $\begin{array}{c}51.37 \\
\mathrm{~d}\end{array}$ & $\begin{array}{c}174.76 \\
\text { s }\end{array}$ & $\begin{array}{c}136.64 \\
\mathrm{~s}\end{array}$ & $\begin{array}{c}126.37 \\
d\end{array}$ & $\begin{array}{c}127.29 \\
\mathrm{~d}\end{array}$ & $\begin{array}{c}128.98 \\
\mathrm{~d}\end{array}$ & $\begin{array}{c}197.45 \\
\text { S }\end{array}$ & $\begin{array}{c}26,89 \\
\mathrm{~s}\end{array}$ \\
\hline
\end{tabular}


The weight average molecular weight of copolymer $(66 \%$ mol. APMI) is 37800 .

The IR spectra of AGC with APMI copolymer $(50 \mathrm{~mol} \%$ APMI) contain several characteristic bands that are useful to the structural characterization of the polymers. We observe characteristic aliphatic methylene stretches between 3100 and $2850 \mathrm{~cm}^{-1}$ and maleimide $\mathrm{C}=\mathrm{O}$ stretches are seen at 1773 and $1701 \mathrm{~cm}^{-1}$. The broadened carbonyl band at $1701 \mathrm{~cm}^{-1}$ in copolymer is the result of spectral overlap between the maleimide $\mathrm{C}=\mathrm{O}$ stretch and the acetyl $\mathrm{C}=\mathrm{O}$ stretch.

The structure of the copolymer obtained was investigated using both ${ }^{1} \mathrm{H}$ and ${ }^{13} \mathrm{C}$ NMR. In ${ }^{1} \mathrm{H}$ NMR spectrum of copolymer $2 \mathrm{H}(\mathrm{CH}-\mathrm{CH}), 3 \mathrm{H}\left(\mathrm{CH}_{3}\right)$ of maleimide unit appeared at $\delta 3.85(\mathrm{~m})$ and 2.59 (d) ppm, respectively. The peaks observed at $\delta 3.25$ and $1.14 \mathrm{ppm}$ are assigned to protons of $-\mathrm{N}\left(-\mathrm{CH}_{2}-\mathrm{CH}_{3}\right)_{2}$ group. The peaks at $\delta 1.72,1.58,1.4 \mathrm{ppm}$ are assigned to protons in pyrrolidinium ring and protons of $\mathrm{CH}_{2}$ group connected with APMI.

Chemical shift values and signals multiplets of the atoms in ${ }^{13} \mathrm{C}$ NMR spectrum of copolymer is presented in Table 1 . The characteristic peaks observed in this study were similar to those for the copolymers obtained by copolymerization of AGC with $\mathrm{N}$-substituted maleimides[17]. The peaks at 26.89 and $197.45 \mathrm{ppm}$ in the spectrum are attributed to the carbons of acetyl group.

As it was shown in[17], AGC and N-substituted maleimides represent monomer pairs with a strong tendency toward radical alternating copolymerization.

Figure 1 shows the composition of copolymers of AGC with APMI versus the composition of initial mixtures.

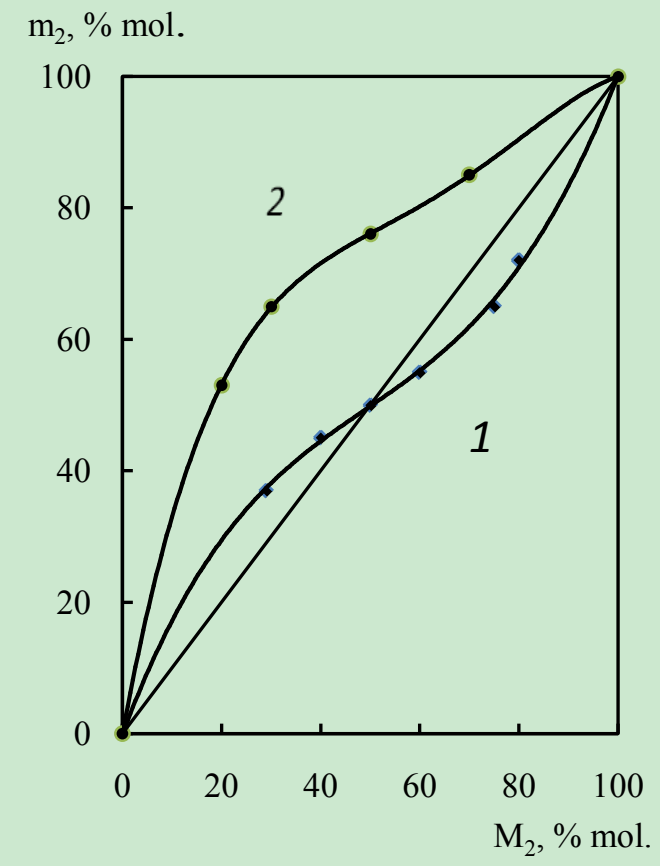

Figure 1. Composition of AGC-APMI copolymers vs. composition of the initial monomer mixture: $\mathrm{M}_{2}$ and $\mathrm{m}_{2}$ are the molar fractions of APMI in the initial mixture and in the copolymer. $[\mathrm{AIBN}]=0.03 \mathrm{~mol} / \mathrm{l} ; T=80^{\circ} \mathrm{C} .1$ DMFA, $[\mathrm{AGC}+\mathrm{APMI}]=1.4 \mathrm{~mol} / \mathrm{l} ; 2$ - in bulk
As it is seen from the diagram of copolymer composition, the activity of maleimide for the reaction in bulk is higher than that in DMFA. As it can be seen, the curve of copolymer composition in DMFA has azeotropic point: the copolymer composition corresponds to the composition of the initial monomer mixture at $50 \%$ mol. APMI. For this system the reactions between dissimilar radicals and monomers occur more easily than those involving similar radicals.

In recent work[17] the maleimides were the more active: $\mathrm{r}_{\mathrm{AGC}}=0.07, \mathrm{r}_{\mathrm{PMI}}=0.14 ; \mathrm{r}_{\mathrm{AGC}}=0.03, \mathrm{r}_{\mathrm{KPMI}}=0.29$. In our case, the monomer APMI is also more active. Effective reactivity ratios for AGC $\left(\mathrm{M}_{1}\right)$ and APMI $\left(\mathrm{M}_{2}\right)$ are given in Table 2. The reactivity ratios obtained from the three methods are in good agreement within the experimental error.

Table 2. Reactivity Ratios for the Copolymers AGC $\left(\mathrm{M}_{1}\right)$ with APMI $80^{\circ} \mathrm{C}$, AIBN (3\%)

\begin{tabular}{|c|c|c|c|c|}
\hline Medium & $r_{1}$ & $r_{2}$ & $r_{1} r_{2}$ & $r_{1} / r_{2}$ \\
\hline DMFA & $0.33 \pm 0.03$ & $0.35 \pm 0.03$ & 0.116 & 0.94 \\
In bulk & $0.10 \pm 0.01$ & $1.68 \pm 0.04$ & 0.168 & 0.06 \\
\hline
\end{tabular}

Comparing PMI, KPMI and APMI to AGC it should be stated that two monomers (PMI and KPMI) show similar copolymerization behaviour. The reactivities of these monomers are close together. There is a question as to whether the para derivative should behave similarly. Due to the presence of the acetyl groups, perhaps, there is a difference at monomer reactivity ratio values of APMI-AGC copolymer. It is shown that copolymerization in bulk and in solution proceeds to form copolymers with random distribution of monomer units.

\subsection{Kinetic Regularities of Copolymerization}

The study of AGC-APMI copolymerization showed a strong dependence of reaction rate on the monomer ratio. The rate of copolymerization of $\mathrm{AGC}\left(\mathrm{M}_{1}\right)$ with APMI reduces with the increasing of molar fraction of $\mathrm{AGC}$ in the initial monomer mixture(Figure 2).

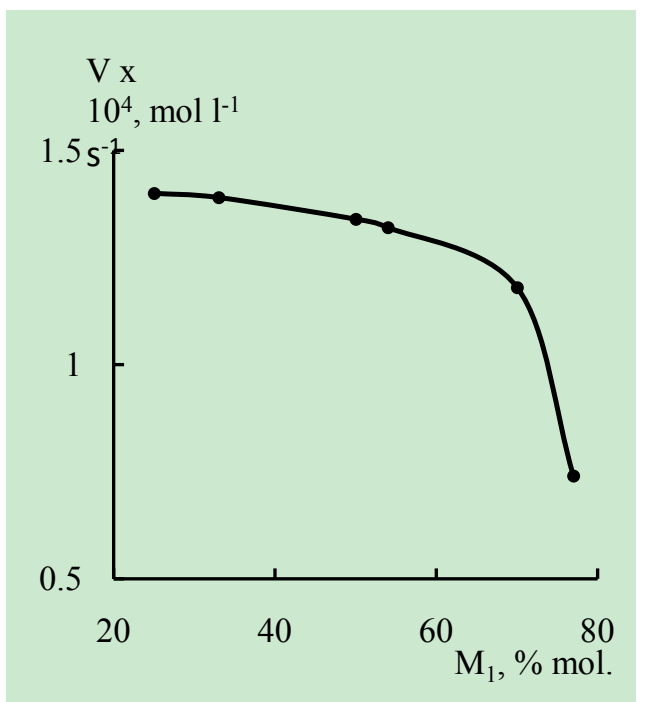

Figure 2. Rate of copolymerization of AGC $\left(\mathrm{M}_{1}\right)$ with APMI vs. monomer ratio. DMFA, $\left[\mathrm{M}_{1}+\mathrm{M}_{2}\right]=1.4 \mathrm{~mol} \cdot \mathrm{L}^{-1},[\mathrm{AIBN}]=0.03 \mathrm{~mol} \cdot \mathrm{L}^{-1}, \mathrm{~T}=80^{\circ} \mathrm{C}$ 
As a result of kinetic investigations at initial conversions, it was determined that the reaction order of $1 / 2$ with respect to initiator concentration typical for radical polymerization is observed, indicating bimolecular mechanism of the growing chain termination, as well as deficiency of chain transfer to the monomer, typical for allyl monomers. The reaction order with respect to the monomer is 1 , which is also characteristic of radical polymerization.

The reaction rate at the studied temperature range $\left(60-90^{\circ} \mathrm{C}\right)$ increases with the temperature independently of the medium. The values of the total activation energy of AGC copolymerization with APMI in DMFA, calculated from Arrhenius equation, are $87.0 \pm 2.0 \mathrm{~kJ} \cdot \mathrm{mol}^{-1}$. This value is in good agreement within the reference data[25] that the values of activation energy of the most reactions of free-radical polymerization are in the range 83.7-96.3 $\mathrm{kJ} \cdot \mathrm{mol}^{-1}$.

\subsection{Thermal analysis}

The thermal behaviour of the synthesized copolymers was investigated by TGA and DSC. It is known that glass transitions of polymaleimides are difficult to observed because they exhibit low changes in heat capacity [26] and are very broad. At heating rate of $10^{\circ} \mathrm{C} \mathrm{min}^{-1}$ the copolymer showed broad scarcely noticeable glass transition. That is why the scan rate of $30^{\circ} \mathrm{C} \mathrm{min}^{-1}$ was used. The $\mathrm{T}_{\mathrm{g}}$ values for the AGC-APMI copolymer ( $66 \% \mathrm{~mol}$. APMI) is $222^{\circ} \mathrm{C}$ (Figure 3 ). The $T_{g}$ values for the AGC-APMI copolymers range between 175 and $228^{\circ} \mathrm{C}$. $\mathrm{T}_{\mathrm{g}}$ of copolymers increases with the APMI content in the copolymer.

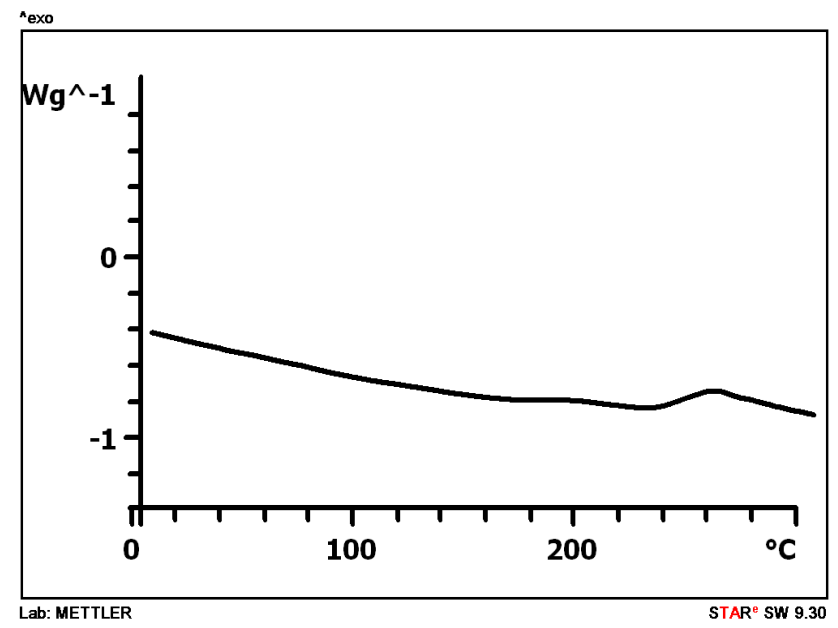

Figure 3. DSC curve of the AGC-APMI copolymer ( $66 \%$ mol. APMI)

The thermal stability of the AGC-APMI copolymers was studied by thermogravimetric analysis over a temperature range from room temperature to $800^{\circ} \mathrm{C}$ under air atmosphere at heating rate of $10^{\circ} \mathrm{C} \mathrm{min}-1$ (Figure 4).

Copolymers showed a one-step mass loss process with a slow decomposition process in the range of $220-600^{\circ} \mathrm{C}$. The TGA results are summarized in Table 3 . It can be seen that the polymers examined are stable at temperatures up to $300^{\circ} \mathrm{C}$

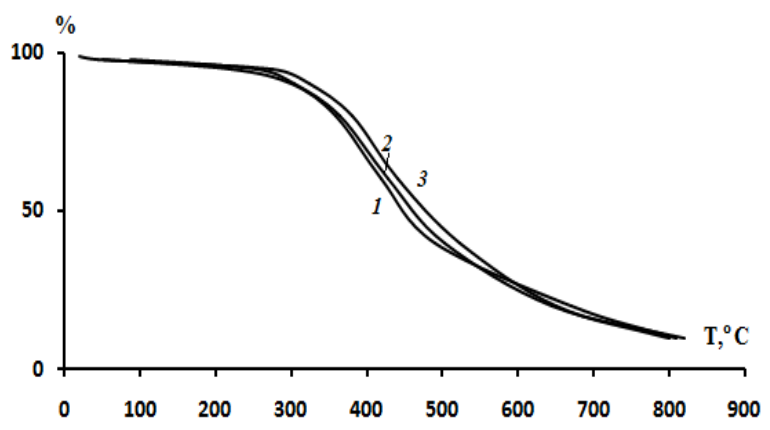

Figure 4. TG curves of the AGC-APMI copolymers: $1-37 \%$ mol. APMI; $2-52 \%$ mol. APMI; $3-52 \%$ mol. APMI

Table 3. TGA Data for the Copolymer

\begin{tabular}{|c|c|c|c|c|c|}
\hline \multirow{2}{*}{ APMI, \%mol. } & \multicolumn{5}{|c|}{ Temperature corresponding to the weight loss } \\
\cline { 2 - 6 } & $5 \%$ & $10 \%$ & $20 \%$ & $40 \%$ & $60 \%$ \\
\hline 37 & 220 & 300 & 358 & 419 & 490 \\
\hline 52 & 255 & 305 & 365 & 429 & 502 \\
\hline 66 & 280 & 319 & 380 & 434 & 523 \\
\hline
\end{tabular}

\subsection{Biological activity}

Antimicrobial agents are defined as those materials capable of killing pathogenic micro-organisms. The great limitations of low molecular weight compounds are based on their residual toxicity even when suitable amounts of the agent are added[27]. The use of antimicrobial polymers prevents the limitation of low molecular weight analogues: reduces the residual toxicity and increases efficiency and selectivity of the agents. Moreover antimicrobial polymers are chemically stable and do not permeate through skin.

Copolymers AGC with APMI were found to be nontoxic (the $\mathrm{LD}_{50}$ values were more $1000 \mathrm{mg} \cdot \mathrm{kg}^{-1}$ ) and therefore could be used for medical purposes. The studies on antibacterial activity showed that copolymer has a pronounced antimicrobial activities with respect to Gram positive microflora. According to the results obtained the minimal bacteriostatic concentration of the copolymer with respect to Staphylococcus aureus and Micrococcus luteus is observed at $15.6 \mu \mathrm{g} \cdot \mathrm{ml}^{-1}$, with respect to Staphylococcus saprophyticus - at $31.2 \mu \mathrm{g} \cdot \mathrm{ml}^{-1}$ of copolymer.

\section{Conclusions}

Copolymers of 2,2-diallyl-1,1,3,3-tetraethylquanidiniumc hloride with $\mathrm{N}-(4$-acetylphenyl)maleimide have been prepared by free-radical copolymerization in dimethylformamide and in bulk at $80^{\circ} \mathrm{C}$. The reactivity ratios of the copolymers were estimated using linear graphical Mayo-Lewis, Fineman-Ross and Kelen-Tüdös methods. For the system the $\mathrm{r}_{\mathrm{APMI}}$ values are higher than the $\mathrm{r}_{\mathrm{AGC}}$ values this fact confirms the higher reactivity of APMI compared with that of AGC. The TGA results for the copolymers show that they are stable at temperatures up to $300^{\circ} \mathrm{C}$. The copolymer obtained has a pronounced antimicrobial activities with respect to Gram positive microflora. 


\section{ACKNOWLEDGEMENTS}

Financial support by the Russian Foundation for Basic Reseach (grant № 11-03-96003-r_ural) and Government Research Program (kontrakt № 11.519.11.2033) is gratefully acknowledged.

\section{REFERENCES}

[1] Mikhailin Yu. A., Miichenko I. P., Maleimide binders, Plast. Massy, № 5, p. 56-64, 1992.

[2] Chang J.Y., Kim T.J., Han M.J., Chae K.H., Polymerization of N-[4-(azidocarbonyl)phenyl]maleimide and N-[4-(N'-phe noxycarbonylamino)phenyl]maleimide polymers containing aromatic isocyanate precursor, Polymer, V. 4, p. 4049-4054, 1999.

[3] Satoru Amou, Shin Nishimura, Akio Takahashi, Tokio Hagiwara, Hiroshi Hamana, Tadashi Narita, Synthesis and polymerization of N-(4-tetrahydropyranyloxyphenyl)maleimide, J. Polym. Sci., Part A: Polym. Chem., V. 37, p. 341-347, 1999.

[4] Hynkova V., Hrabak F., Copolymerization characteristics of $\mathrm{N}-(2,4,6$-tribromphenyl)maleimide and N-(2,3,4,5,6-pentabr omphenyl)maleimide with butadiene and styrene, J. Polym. Sci., Part A:Polym. Chem., V. 14, p. 2587-2588, 1976.

[5] Jidong He, Juan Wang, Sidong Li, Study on the kinetics of copolymerization of $\mathrm{N}-n$-substituted phenylmaleimides with styrene in solution, Xuebao Gaofenzi, № 5, p. 559-262, 2000.

[6] Gi Heon Kim, Chang Dae Keum, Sung Jin Kim, Lee Soon Park, Synthesis of nonlinear optical maleimide copolymer by polymer reaction and their electro-optic properties, J. Polym. Sci., Part A: Polym. Chem., V. 37, p. 3715-3722, 1999.

[7] Xulin Jiang, Yalan Zhong, Deyue Yan, Hui Yu, Dezhin Zhang, Hyperbranched copolymers of p-(chloromethyl)styre ne and $\mathrm{N}$-cyclohexylmaleimide synthesized by atom transfer radical polymerization, J. Appl.Polym. Sci., V. 78, p. 1992-1997, 2000.

[8] Ki Hong Park, Jong Tae Lim, Sangyup Song, Mi Gyung Kwak, Chul Joo Lee, Nakjoong Kim, Nonlinear optical polymers with novel benzoxazole methacrylate chromophores. IV. Synthesis of maleimide-styrene and maleimide- methacrylate copolymers, React. Funct. Polym., V. 40, p. 169-175, 1999.

[9] Guo-Rong Shan, Zhi-Xue Weng, Zhi-Ming Huang, Zu-Ren Pan, Studies on the microstructure of vinyl $/ \mathrm{N}$ - phenylmaleimide copolymers by NMR and their applications, J. Appl. Polym. Sci., V. 77, p. 2581-2587, 2000.

[10] Vishal Anand, Veena Choudhary, Studies on the copolymerization of $\mathrm{N}$-arylmaleimides with alkyl(meth)acrylate, Macromol.Chem. Phys., V. 202, p. 943-948, 2001.

[11] Kalinina F.E., Mognonov D.M., Radnaeva L.D., Vasnev V.A., Alternating copolymers of vinylglycidyl ether and imides, Polymer Science, A, V. 44, p. 238-242, 2002.
[12] Kalinina F.E., Radnaeva L.D., Mognonov D.M., Vasnev V.A., Nedolya N.A., Trofimov B.A., Copolymers of 3(2- vinyloxyethoxy)propylene-1,2-carbonate and N-phenylmaleimide, Polymer Science, B, V. 46, p. 182-186, 2004.

[13] Rasulov N.Sh., Medyakova L.V., Kulieva E.Yu., Rzaev Z.M., Zubov V.P., Altewrnating copolymerization of N- phenylmaleimide and cyclohexylvinylketone, Polymer Science, A, V. 28, p. 2595-2600, 1986.

[14] Chemical Encyclopedia, Ed. by I. L. Knunyants, Sovetskaya Entsiklopediya, Moscow, 1988.

[15] Ikeda T., Tazuke S. Biocidal polycations, Polym Prepr., V. 26, p. 226-227, 1985.

[16] Gilbert P., Moore L.E. Cationic antiseptics: diversity of action under a common epithet, J Appl Microbiol., V. 99, p. 703-715, 2005.

[17] Gorbunova M.N. Copolymerization of 2,2-Diallyl-1,1,3,3-tet raethylguanidinium Chloride with $\mathrm{N}$-substituted maleimides, Polym. Sci. B., V. 52, № 7-8, P. 473-479, 2010.

[18] Vorob'eva A.I., Sagitova D.R., Gorbunova M.N., Muslukhov R.R., Kolesov S.V., Tolstikov A.G., Monakov Yu.B., Activity of diallylamido-bis(diethylamido)guanidinium chloride in radical polymerization reactions, Polymer Science B, V. 49, p. 172-176, 2007.

[19] Fieser L., Fieser M., Reagents for Organic Synthesis, Wiley, New York, 1968; Mir, Moscow, 1971.

[20] Gordon A.J., Ford R. A., The Chemist's Companion:A Handbook of Practical Data, Techniques and References, Wiley, New York, 1972.

[21] Mayo F.R., Lewis F.J., Abasis for comparing the behavior of monomers in copolymerization; the copolymerization of sturene and metyl methacrylate, J. Am. Chem. Soc., V. 66, p. 1594-1601, 1944.

[22] Finemann M., Ross S.D., Linear method for determining monomer reactivity ratios in copolymerization, J. Polym. Sci., V. 5, p. 269-284, 1950.

[23] Kelen T., Tüdös F., Analysis of the linear methods for determining copolymerization reactivity ratios. I. A new improved linear graphic method, J. Macromol. Sci., Chem., V. 9, p. $1-27,1975$.

[24] Prozorovskiy V.B., Prozorovskaya M.P., Demchenko V.M., Express-method of effective dose determination and its mistakes, Pharmacol. and toxicol, № 4, p. 497-502, 1978.

[25] Kabanov V.A., Zubov V.P., Semchikov Yu.D., ComplexRadical Polymerization, Khimiya, Moscow, 1987.

[26] Noordegraaf M.A., Kuiper G.J., Marcelis A.T.M., Sudholter E.J.R., Rigid maleimide-alt-vinylpyridine copolymers with pendant chromophores. Synthesis, characterization and monolayer formation, Macromol. Chem. Phys., V. 198, p. 3681-3697, 1997.

[27] Rivas B.L., Pereira E., Maureira A., Functional water-soluble polymers: polymer-metal ion removal and biocide properties, Polym Int, V. 58, p. 1093-1114, 2009. 